\title{
The Landsat observation record of Canada: 1972-2012
}

Joanne C. White ${ }^{1 *}$, Michael A. Wulder ${ }^{1}$

${ }^{1}$ Canadian Forest Service (Pacific Forestry Centre), Natural Resources Canada, 506 West Burnside Road, Victoria, British Columbia, V8Z 1M5, Canada

*Corresponding author:

Email: joanne.white@nrcan.gc.ca

Keywords: Landsat, archive, Canada, metadata, monitoring, time series

\author{
Pre-print of published version \\ Reference: \\ White, J.C., Wulder, M.A. 2013. The Landsat observation record of Canada: 1972-2012. \\ Canadian Journal of Remote Sensing, Vol. 39, No.6, pp. 455-467. \\ DOI: \\ http://dx.doi.org/10.5589/m13-053

\section{Disclaimer:} \\ The PDF document is a copy of the final version of this manuscript that was subsequently \\ accepted by the journal for publication. The paper has been through peer review, but has not \\ been subject to any additional copy-editing or journal specific formatting (so will look \\ different from the final version of record, which may be accessed following the DOI above \\ depending on your access situation).
}




\section{Abstract}

The Landsat data archive represents more than 40 years of earth observation, providing a valuable information source for monitoring ecosystem dynamics. In excess of 605,000 images of Canada have been acquired by the Landsat program since 1972. Herein we report several spatial and temporal characteristics of the Landsat observation record for Canada (1972-2012), including image availability by year, growing season, sensor, ecozone, and provincial or territorial jurisdiction. In contrast to the global Landsat archive, which is dominated by Enhanced Thematic Mapper Plus (ETM+) data, the majority of archived Landsat images of Canada were acquired by the Thematic Mapper (TM) sensor (57\%). Approximately 55\% of archived Landsat images were acquired within \pm 30 days of August 1, and 74\% of WRS-2 path/row locations in Canada have more than 200 images acquired between June 1 and September 30. Issues such as cloud cover and the availability of imagery to support pixel-based image compositing and time series analyses are explored and documented. For a pixel-based image compositing scenario whereby images (TM and ETM+) acquired after 1981 with less than $70 \%$ cloud cover and a target date of August $1 \pm 30$ days are considered, $60 \%$ of the path/row locations have 5 or fewer years of missing data in the archive. For time series analyses (i.e., ecosystem monitoring scenario) with the same temporal constraint but with less than $10 \%$ cloud cover, only $2 \%$ of path/row locations are missing 5 or fewer years of data, with a mean and median of 17 years of missing data. However, if a broader temporal window (June 1 to September 30) is considered for this scenario, 18\% of path/row locations have 5 or fewer years of missing data. Free and open-access to the Landsat data archive, combined with the continuity of new data collections provided by the recently 
launched Landsat 8 satellite, offer many opportunities for scientific inquiry concerning the status and trends of Canada's terrestrial ecosystems.

\section{Introduction}

Since 1972 Landsat has provided information on the status and dynamics of Canada's terrestrial ecosystems at a spatial resolution that captures the impacts of human activities (Townshend and Justice, 1988). Landsat has played an important role in mapping Canada's land cover (Wulder et al., 2008; Olthof et al., 2009), monitoring disturbance events (Skakun et al. 2003; Schroeder et al., 2011; Pasher et al., 2013), and characterizing long-term changes in vegetation cover (Fraser et al., 2009; 2011; McManus et al., 2012; Valeria et al., 2012). Landsat data has also been used for a number of other applications, including the assessment of wildlife habitat (White et al., 2011; Chen et al., 2013), geomorphological applications (Tenant et al., 2012; Bolch et al., 2010), and monitoring of urban expansion (Furberg and Ban, 2012), to name but a few.

In 1992, the United States Congress mandated the establishment of a permanent government-held earth observation archive, which was to include the long-term Landsat data record (Goward et al., 2006). Significant changes to the Landsat data distribution policy in 2008 made the entire Landsat data archive and all newly acquired Landsat data held by the United States Geological Survey (USGS), freely and openly available to the global community (Woodcock et al., 2008; Wulder et al. 2012). At the time of writing, more than 12 million images have been downloaded from the archive since December 8, 2008. ${ }^{1}$ Free and open access to the Landsat archive has greatly increased the use of

\footnotetext{
${ }^{1}$ http://landsat.usgs.gov/Landsat_Project_Statistics.php
} 
Landsat data for science and applications purposes (National Research Council, 2013), especially for large jurisdictions such as Canada.

Since the launch of Landsat 1 on July 23, 1972, sensors onboard the Landsat series of satellites, including Multispectral Scanner (MSS), Thematic Mapper (TM), and Enhanced Thematic Mapper Plus (ETM+), have acquired more than 605,000 images of Canada, providing the longest continuous earth observation record of Canada's terrestrial ecosystems. MSS data was acquired by Landsats 1-5 from 1972 to 1992 (and again briefly in 2012); TM data was acquired by Landsats 4 and 5 from 1982 until 2011; and ETM+ data have been acquired by Landsat 7 since 1999 (Williams et al., 2006). In February 2013, Landsat 8 was successfully launched and is currently acquiring data with two independent sensors: the Operational Land Imager (OLI) and the Thermal Infrared Sensor (TIRS). Specifications for Landsat sensors operating from 1972 to 2012 are summarized in Table 1.

At the time of writing, the Landsat archive is estimated to hold approximately 4 million images of the globe. ${ }^{2}$ Since the inception of the Landsat program, Canada has played an active role as an International Cooperator, building a data receiving station in Prince Albert, Saskatchewan in 1972, which was the first station outside the United States to receive data from Landsat 1 (Draeger et al., 1997). A second receiving station, built in Gatineau, Quebec in 1985, further expanded coverage to the complete land area and coastlines of Canada. Both receiving stations are operated by the Canada Centre for Remote Sensing (CCRS), Natural Resources Canada. ${ }^{3,4}$

\footnotetext{
${ }^{2}$ http://landsat.usgs.gov/metadatalist.php (downloaded June 21, 2013).

3 http://www.nrcan.gc.ca/earth-sciences/products-services/satellite-photography-imagery/satellitefacilities/2348
} 
Due to factors such as onboard recording and downlink capacity prior to Landsat 8, a global network of receiving stations known as International Cooperators were required to receive Landsat data (Goward et al., 2006). A comprehensive assessment of the global Landsat archive in 2006 revealed the existence of many spatial and temporal gaps in the archive, arising from a variety of technical and administrative causes (Goward et al., 2006; Williams et al., 2006). In an effort to address these gaps, the USGS has actively sought to repatriate all unique imagery held by International Cooperators; as of August 1, 2013, more than 2.2 million images have been acquired from International Cooperators and integrated into the archive. ${ }^{5}$ Approximately 378,355 unique Landsat images acquired by Canadian receiving stations have been provided to the USGS since 2009 (Kline, 2013). At the time of writing, all of these images have been incorporated into the USGS archive with the exception of 137,000 MSS images that are currently in the process of being added to the archive. ${ }^{6}$

The USGS stopped acquiring TM data from the Landsat 5 satellite in November 2011 - after a 27-year period that far exceeded its original 3-year design life. ${ }^{7}$ Presently, Landsats 7 and 8 acquire image data on a daily basis. Landsat 7 is projected to have sufficient fuel to enable data acquisition until 2017. ${ }^{8}$ Since May 31, 2003, the Scan Line Corrector (SLC) of the ETM+ sensor has been inoperable, resulting in images with gaps towards the scene edges (Williams et al., 2006). The SLC-off data acquired after the malfunction remains of comparable quality to data collected prior to the malfunction and

\footnotetext{
${ }^{4}$ http://landsat.usgs.gov/about_ground_stations.php

5 http://landsat.usgs.gov/about_LU_Vol_7_Issue_4.php\#1a

6 http://landsat.usgs.gov/mission_headlines2013.php; see July 8, 2013.

7 http://landsat.usgs.gov/L5_Decommission.php

8 http://landsat.gsfc.nasa.gov/?p=1900
} 
several approaches have been implemented to fill in the SLC-off gaps (e.g., Maxwell, 2004; Maxwell et al., 2007).

To optimize the distribution of images for acquisition of seasonal, global, cloudfree collections of land observations, increasingly sophisticated collection plans are implemented. For instance, the Long-Term Acquisition Plan (LTAP) described by Arvidson et al. (2001; 2006) ensures that more images are acquired in those areas that are experiencing seasonal change (i.e., vegetation growth or senescence). Building upon these previous experiences, Landsat 8 has a similar LTAP, although with a greater number of potential collects per day (more than 400 images per day versus the 350 images per day acquired by Landsat 7). Landsat 8 also has large capacity on-board data recorders and high bandwidth (S-band) downlink enabling all data collected to be stored and transmitted to a central receiving station (Sioux Falls, South Dakota) (Irons et al., 2012).

Various studies have examined the Landsat archive, either to interrogate for global coverage, to support specific applications, or to assess holdings for specific jurisdictions (Fuller et al., 1994; Goward et al., 2006; Ju and Roy, 2007; Kovalksyy and Roy, 2012). To the authors' knowledge, no studies have specifically examined and reported on the availability of archived Landsat images for Canada. In this communication, we describe the Landsat observation record for Canada from 1972 to 2012, providing insights on the source (i.e., sensor) and spatial and temporal distributions of Landsat images that have been acquired during this period. Issues such as cloud cover and the availability of imagery to support pixel-based image compositing and time series analyses are also explored and documented. 


\section{Data and Methods}

Metadata for all images held in the Landsat archive were acquired from the USGS Bulk Metadata Service. ${ }^{9}$ Separate metadata files were acquired for Landsat 1-3 MSS, Landsat 4-5 MSS, Landsat 4-5 TM, Landsat 7 ETM+, and Landsat 7 ETM+ (SLC-off). The metadata records include a variety of attributes, which vary by sensor. Attributes common to all sensors that were used in this analysis included: unique scene identification number (scene id), sensor, acquisition date, Worldwide Reference System (WRS) path and row, and cloud cover percentage (overall and by quadrant).

The WRS is a spatial index used for cataloguing Landsat data. The globe is partitioned into frames, indicating the extent of each Landsat image, and these frames are defined using paths (parallel to the ground track of the satellite, north/south) and rows (parallel to latitude). Landsat satellites 1-3 used WRS-1, and all subsequent Landsat satellites have used WRS-2. Since the WRS-1 and WRS-2 systems differ, it was necessary to harmonize WRS-1 path/rows to WRS-2 path/rows. This was done via a spatial overlay: digital geographic files for the WRS-1 and WRS-2 were acquired from the $\mathrm{USGS}^{10}$ and the centroids (points) of WRS-1 frames were overlaid on the WRS-2 frames (polygons) and were assigned the corresponding WRS-2 path/row. Both WRS-1 and WRS-2 frames overlap, with the amount of overlap increases with increasing latitude (Wulder and Seemann, 2001). In cases where the centroid of a WRS-1 image was found within multiple overlapping WRS-2 frames, the WRS-1 centroid was arbitrarily assigned to a single WRS-2 frame (path/row). After harmonization of WRS-1 and WRS-2, all metadata records were compiled into a single database. Data records were subsequently

\footnotetext{
${ }^{9}$ http://landsat.usgs.gov/metadatalist.php (downloaded June 21, 2013).

${ }^{10} \mathrm{http} / / /$ landsat.usgs.gov/worldwide_reference_system_WRS.php
} 
filtered to retain only those records corresponding to images with WRS-2 path/rows over Canada's terrestrial area, acquired in the period 1972 to 2012. In total, there were 1224 unique WRS-2 path/row locations that were included in this analysis.

To further characterize the temporal aspects of the Landsat archive of Canada, we considered a broad definition for the growing season to be June 1 to September 30 (Julian dates 152 to 273), acknowledging that this range is likely too broad for Canada's northern ecosystems. We also considered the temporal distribution of images relative to a target date of August 1 (Julian date 213), which is considered to be within the growing season of most regions in Canada (McKenney et al., 2006). We considered two different scenarios when querying the archive: long-term ecosystem monitoring (i.e., assuming an image time series approach), and a pixel-based image compositing scenario, whereby the best available pixel observation, determined using a set of criteria such as day of year and cloud cover, are used to build an image composite (e.g., Griffiths et al., 2012), which can then be used to derive other information products such as land cover and land cover change. Landsat imagery was considered suitable for ecosystem monitoring purposes if it was acquired after 1981 and within \pm 30 days of August 1, and had less than $10 \%$ cloud cover. Likewise, imagery considered suitable for pixel-based image compositing was also acquired after 1981 and within \pm 30 days of August 1, but had less than $70 \%$ cloud cover. The 70\% threshold has been used previously for Landsat pixel-based image compositing (Griffiths et al., 2013) and also ensures a sufficient number of cloud-free ground control point (GCP) locations to enable accurate geometric correction. The 1981 threshold was used to exclude MSS images from consideration in the two aforementioned scenarios. 
MSS era images were explicitly excluded from our consideration of scenarios for ecosystem monitoring and pixel-based image compositing for a number of reasons. First, at the time of writing, the integration of MSS images provided to the USGS by CCRS is ongoing, so any interrogation of the archive prior to 1982 would have been incomplete. ${ }^{6}$ Second, MSS imagery does not have the same spatial resolution as TM and ETM+ imagery (Table 1) so special considerations are required to incorporate these data into pixel-based image compositing or time series approaches. Third, MSS image products are known to have lower geometric accuracy than TM and ETM+ and therefore require additional processing prior to integration into these analysis approaches (e.g., Pflugmacher et al., 2012). Lastly, the MSS sensor lacks a band in the shortwave infrared, which is an important spectral region for vegetation monitoring (Cohen and Goward, 2004).

\section{The Landsat observation record of Canada (1972-2012)}

At the time of writing, there are a total of 605,981 images in the Landsat data archive of Canada. More than half of these images (57\%) are TM, followed by ETM+ SLC-off (16\%), MSS (16\%), and ETM+ (10\%). This contrasts with the composition of the global USGS Landsat archive, which has been documented to contain a greater proportion of Landsat 7 ETM+ (and ETM+ SLC-off) data relative to data from other Landsat sensors (Roy et al. 2010a). This difference in archive composition may be explained by sun angle limitations that are imposed on Landsat 7 acquisitions. Unlike previous Landsat sensors, Landsat 7 acquisitions are limited in areas with insufficient sunlight and this limitation has the greatest impact on acquisitions in high latitude regions such as Canada. Minimum 
sun angle constraints for Landsat 7 acquisitions are 15 degrees in the northern hemisphere and 5 degrees in the southern hemisphere. ${ }^{11}$

The distribution of archived Landsat images for Canada, by year and by sensor, is illustrated in Figure 1. In 2004 (the year with the greatest number of Landsat images in the archive), more than 32,000 images were acquired: 17,531 TM and 14,652 ETM+ SLC-off images. Figure 1 indicates the decline in MSS acquisitions from 1978 to 1982 when both Landsat 2 and Landsat 3 had technical issues (Goward et al. 2006), as well as the relatively short-term collection of ETM+ prior to the aforementioned Scan Line Corrector failure in 2003. In 2000 there was a marked decrease in TM acquisitions over Canada, with only 2110 TM images acquired in that year.

Table 2 shows the distribution of archived images by provincial and territorial jurisdictions and by ecozone. While larger jurisdictions/ecozones will have more path/row locations (and thereby more images) as a function of their larger size, northern jurisdictions/ecozones will have more images as a function of overlap between Landsat frames. Nunavut has the largest number of Landsat images, with more than 130,000 in the archive, followed by Quebec $(87,523)$ and Ontario $(83,661)$. Monitoring of northern ecosystems can take advantage of significant image overlap that is approximately $85 \%$ at 80 degrees latitude, versus $40 \%$ overlap at Canada's southern border with the United States (Wulder and Seemann, 2001).

By design, more Landsat images are acquired during the growing season than in the winter months, an operational criteria that was fully realized with the advent of the LTAP for Landsat 7 (Arvidson et al., 2006). Figures 2A and 2B indicate the within-year

\footnotetext{
${ }^{11}$ http://landsat.usgs.gov/sun_angle_limits_landsat_acquisitions.php
} 
distribution of images relative to an August 1 target date: approximately 55\% of the archived Landsat imagery of Canada was acquired within \pm 30 days of August 1 . The mean Julian day of acquisition of archived images is July 6, the median is July 9, and the mode is July 30.

The spatial distribution of all archived Landsat images of Canada by WRS-2 path/row centroids is shown in Figure 3A, with southern areas of Canada generally having more archived imagery per path/row than more northern areas, primarily as a result of the greater number of receiving stations in the south and their relative catchment areas, as well as the priority given for acquisition of the conterminous United States and the aforementioned sun angle limits imposed on Landsat 7 acquisitions. Figure 3B shows the spatial distribution of archived images for the growing season exclusively (June 1 to September 30), with approximately 74\% path/row locations in Canada’s terrestrial areas having more than 200 archived images acquired within this period for the years 1972 2012.

The quality of the archived images can be evaluated using the cloud cover percentages reported in the metadata. Methods to determine the percentage of cloud cover in a given Landsat image have varied by mission: Landsats 1-5 MSS data were assessed manually, Landsat 4-5 TM data were assessed using an Automated Cloud Cover Assessment (ACCA) algorithm (Su, 1984), and Landsat 7 ETM+ and ETM+ SLC-off data are assessed using a more complex ACCA algorithm (Irish et al., 2006). Cloud cover is reported for the image overall, and separately for each image quadrant. The distribution of Canada’s Landsat archived images by their percent cloud cover is bi-modal (Figure 4), with one-third of images having either less than $10 \%$ or more than $90 \%$ cloud cover. The 
relative distribution of archived images by month of the growing season is also shown in Figure 4 and indicates that images acquired in the month of July generally have a lower percent cloud cover than images acquired in the month of September. Figure 5 shows the spatial distribution of TM and ETM+ archived images acquired within the growing season that have less than 70\% (Figure 5A) and less than 10\% (Figure 5B) cloud cover, respectively. Overall, approximately $48 \%$ of archived Landsat images of Canada were acquired within the growing season and of these, 59\% have less than 70\% cloud cover, and $19 \%$ have less than $10 \%$ cloud cover.

Tolerance for clouds and cloud shadows will depend on the end user's application. Pixel-based image compositing approaches that seek to identify the best available pixel within a certain temporal window, and which may consider images from years prior or subsequent to a given target year (e.g., Griffiths et al., 2013), will likely tolerate a much greater proportion of cloud cover (Figure 5A). There is however a practical limit to the amount of cloud cover that can be tolerated for image compositing. For example, although Landsat images with more than 90\% cloud cover may be considered useable from a compositing perspective, images with this amount of cloud cover are difficult to geometrically correct as clouds will obscure GCP locations, thereby reducing the number of GCPs available for correction (Roy et al., 2010b). In contrast, ecosystem monitoring applications may require cloud-free or almost cloud-free imagery (Figure 5B). Similarly, applications that require knowledge of conditions on a specific date, such as monitoring of deforestation events, have a greater need for cloud-free imagery.

These different cloud cover scenarios are further explored in Figure 6 where all non-MSS images acquired after 1981 are considered. Both Figures 6A and 6B indicate 
that there are temporal gaps in the archive for these two scenarios. For a pixel-based image compositing scenario whereby less than $70 \%$ cloud cover and a target date of August $1 \pm 30$ days are considered, 60\% of the Landsat path/row locations are missing 5 or fewer years of data (Figure 6A). When combined with the results presented in Figure 5A for the overall number of images acquired, it would appear that the Landsat archive of Canada is capable of supporting a pixel-based image compositing approach for much of Canada's terrestrial area. For an ecosystem monitoring scenario, whereby images likewise must be acquired within \pm 30 days of August 1 , but with less than $10 \%$ cloud cover, Figure 6B indicates that only $2 \%$ of Landsat path/row locations are missing 5 or fewer years of data. The mean and median number of years with missing data for this scenario was 17, with the only Landsat path/row locations that satisfy the scenario's criteria being located in the Prairies Ecozone (with one exception in southern Ontario for Path 17, Row 29). However, if the acquisition date for this scenario is expanded to include our broader definition of the growing season (June 1 to September 30), some potential ecosystem monitoring locations can be identified within the forested ecosystems of Canada: Figure 7 indicates that with this broader date range, 18\% of Landsat path/row locations have 5 or fewer years of missing data. The cumulative frequency distributions for WRS-2 path/row locations for all scenarios (Figure 8) illustrate the capacity of the Landsat observation record of Canada to support both time series and pixel-based image compositing approaches. For all scenarios, the goal is to minimize the number of years of missing data, and Figure 8 shows that the more relaxed cloud cover constraint associated with the pixel-based image compositing scenario would result in fewer years of missing data and greater image availability for subsequent analyses. 


\section{Conclusions}

With open access to the Landsat data archive, reconstruction of the history of Canada's terrestrial ecosystems and related dynamics is increasingly possible. Knowledge of prior conditions and trends can inform expectations, aid in parameterizing models, and support the identification of change events. The number and variety of scientific opportunities that could be pursued with the freely available data provided by the Landsat archive are limitless. The spatial, temporal, and cloud cover characteristics of the Landsat archive for Canada, as documented herein, indicate that there is a rich repository of quality imagery available that can support a broad range of methods and approaches, including pixelbased image compositing and time series analyses for long-term ecosystem monitoring.

\section{Acknowledgements}

This research was undertaken as part of the “National Terrestrial Ecosystem Monitoring System (NTEMS): Timely and detailed national cross-sector monitoring for Canada" project jointly funded by the Canadian Space Agency (CSA) Government Related Initiatives Program (GRIP) and the Canadian Forest Service (CFS) of Natural Resources Canada.

\section{References}

Arvidson, T., Gasch, J., Goward, S.N. 2001. Landsat 7’s long-term acquisition plan—an innovative approach to building a global image archive. Remote Sensing of Environment, Vol. 78, No. 1-2, pp. 13-26. 
Arvidson, T., Goward, S., Gasch, J., Williams, D. 2006. Landsat-7 long-term acquisition plan: Development and validation. Photogrammetric Engineering and Remote Sensing, Vol. 72, No. 10, pp. 1137-1146.

Bolch, T., Menounos, B., Wheate, R. 2010. Landsat-based inventory of glaciers in western Canada, 1985-2005. Remote Sensing of Environment, Vol. 114, No. 1, pp. $127-137$.

Cohen, W.B. and Goward S.N. 2004. Landsat's role in ecological applications of remote sensing. BioScience, Vol. 54, No. 6, pp. 535-545.

Chen, W., Russel, D.E., Gunn, A., Croft, B., Chen, W.R., Fernandes, R., Zhao, H., Li, J., Zhang, Y., Koehler, K., Olthof, I., Fraser, R.H., Leblanc, S.G., Henry, G.R., White, R.G., Finstad, G.L. 2013. Monitoring habitat condition changes during winter and pre-calving migration for Bathurst Caribou in northern Canada. Biodiversity, Vol. 14, No. 1., pp. 36-44.

Draeger, W.C., Holm, T.N., Lauer, D.T., Thompson, R.J. 1997. The availability of Landsat data: past, present, and future. Photogrammetric Engineering and Remote Sensing, Vol. 63, No. 7 , pp. 869-875.

Fraser, R.H., Pouliot, O.D. 2009. Monitoring land cover change and ecological integrity in Canada's National Parks. Remote Sensing of Environment, Vol. 113, No. 7, pp. 1397-1409.

Fraser, R.H., Olthof, I., Carrière, Deschamps, A., Pouliot, D. 2011. Detecting long-term changes to vegetation in northern Canada using the Landsat satellite image archive. Environmental Research Letters, Vol. 6, No. 4, pp. 1-9. 
Fuller, R.M., Groom, G.B., Wallis, S.M. 1994. The availability of Landsat TM images of Great Britain. International Journal of Remote Sensing, Vol. 15, No. 6, pp. 13571362.

Furberg, D., Ban, Y. 2012. Satellite monitoring of urban sprawl and assessment of its potential environmental impact in the Greater Toronto Area between 1985 and 2005. Environmental Management, Vol. 50, No. 6, pp. 1068-1088.

Griffiths, P., van der Linden, S., Kuemmerle, T., Hostert, P. 2013. A pixel-based Landsat compositing algorithm for large area land cover monitoring. Journal of Selected Topics in Applied Earth Observations and Remote Sensing, Vol. 238, pp. 1-14.

Goward, S., Arvidson, T., Williams, D., Faundeen, J., Irons, J., Franks, S. 2006. Historical record of Landsat global coverage: Mission operations, NSLRSDA, and international cooperator stations. Photogrammetric Engineering and Remote Sensing, Vol. 72, No. 10, pp. 1155-1169.

Irish, R.R., Barker, J.L., Goward, S.N., Arvidson, T. 2006. Characterization of the Landsat 7 ETM+ Automated Cloud-Cover Assessment (ACCA) algorithm. Photogrammetric Engineering and Remote Sensing, Vol. 72, No. 10, pp. 11791188.

Irons, J.R., Dwyer, J.L., Barsi, J.L. 2012. The next Landsat satellite: The Landsat Data Continuity Mission. Remote Sensing of Environment, Vol. 122, pp. 11-21.

Ju, J., Roy, D.P. 2007. The availability of cloud-free Landsat ETM+ data over the conterminous United States and globally. Remote Sensing of Environment, Vol. 112, pp. 1196-1211. 
Kline, K., 2013. Landsat operations project report. Landsat Science Team Meeting, 12 February 2013, Buelton, CA. Available online: http://landsat.usgs.gov/documents/Kline\%20-\%20Landsat\%20Status\%20\%20LST\%202-2013.pdf

Kovalskyy, V., Roy, D.P. 2013. The global availability of Landsat 5 TM and Landsat 7 ETM+ land surface observations and implications for global $30 \mathrm{~m}$ Landsat data product generation. Remote Sensing of Environment, Vol. 130, pp. 280-293.

Maxwell, S. 2004. Filling Landsat ETM+ SLC-off gaps using a segmentation model approach. Photogrammetric Engineering and Remote Sensing, Vol. 70, No. 10, pp. 1109-1111.

Maxwell, S.K., Schmidt, G.L., Storey, J.C. 2007. A multi-scale segmentation approach to filling gaps in Landsat ETM+ SLC-off images. International Journal of Remote Sensing, Vol., 28, No. 23, pp. 5339-5356.

McKenney, D., Pedlar, J.H., Papadopol, P., Hutchinson, M.F. 2006. The development of 1901-2000 historical monthly climate models for Canada and the United States. Agricultural and Forest Meterology, Vol. 138, pp. 69-81.

McManus, K.M., Morton, D.C., Masek. J.G., Wang, D., Sexton, J.O, Nagol, J.R., Ropars, P., Boudreau, S. 2012. Satellite-based evidence for shrub and graminoid tundra expansion in northern Quebec from 1986 to 2010. Global Change Biology, Vol. 18, No. 7, pp. 2313-2323.

National Research Council. 2013. Landsat and Beyond: Sustaining and Enhancing the Nation's Land Imaging Program. Washington DC: The National Academies Press, 73 pp. 
Olthof, I., Latifovic, R., Pouliot, D. 2009. Development of a circa 2000 land cover map of northern Canada at $30 \mathrm{~m}$ resolution from Landsat. Canadian Journal of Remote Sensing, Vol. 35, No. 2, pp. 152-165.

Pasher, J., Seed, E., Duffe, J. 2013. Development of boreal ecosystem anthropogenic disturbance layers for Canada based on 2008 to 2010 Landsat imagery. Canadian Journal of Remote Sensing, Vol. 39, No. 1, pp. 42-58.

Pflugmacher, D., Cohen, W.B., Kennedy, R.E. 2012. Using Landsat-derived disturbance history (1972-2010) to predict current forest structure. Remote Sensing of Environment, Vol. 122, pp. 146-165.

Roy, D. P., Ju, J., Mbow, C., Frost, P., Loveland, T. 2010a. Accessing free Landsat data via the Internet: Africa's challenge. Remote Sensing Letters, Vol. 1, pp. 111-117.

Roy, D.P., Ju, J., Kline, K., Scaramuzza, P.L., Kovalskyy, V., Hansen, M., Loveland, T.R., Vermote, E., Zhang, C. 2010b. Web-enabled Landsat Data (WELD): Landsat ETM+ composited mosaics of the conterminous United States. Remote Sensing of Environment, Vol. 114, pp. 35-49.

Schroeder, T.A., Wulder, M.A., Healey, S.P., Moisen, G.G. 2011. Mapping wildfire and clearcut harvest disturbances in boreal forests with Landsat time series data. Remote Sensing of Environment, Vol. 115, No. 6, pp. 1421-1433.

Skakun, R.S., Wulder, M.A., Franklin, S.E. 2003. Sensitivity of Thematic Mapper Enhanced Wetness Difference Index to detect mountain pine beetle red-attack damage. Remote Sensing of Environment, Vol. 86, pp. 433-443.

Su, J.J. (1984). Enhanced ACCA Algorithm. Space Imaging Corporation Technical Memo IT81-LSD-SA\&E Memo (pp. 274). 
Tenant, C., Menounos, B., Wheate, R., Clague, J.J. 2012. Area change in glaciers in the Canadian Rocky Mountains, 1919 to 2006. Cryosphere, Vol. 6, No. 6, pp. 15411552.

Townshend, J.R.G. and Justice, C.O. 1988. Selecting the spatial resolution of satellite sensors required for global monitoring of land transformations. International Journal of Remote Sensing,Vol. 9, No. 2, pp. 187-236.

Valeria, O., Laamrani, A., Beaudoin, A. 2012. Monitoring the state of a large boreal forest region in eastern Canada through the use of multitemporal classified satellite imagery. Canadian Journal of Remote Sensing, Vol. 38, No. 1, pp. 91108.

White, J.C., Wulder, M.A., Gomez, C., Stenhouse, G. 2011. A history of habitat dynamics: Characterizing 35 years of stand replacing disturbance. Canadian Journal of Remote Sensing, Vol. 37, No. 2, pp. 234-251.

Williams, D.L., Goward, S., Arvidson, T. 2006. Landsat: Yesterday, Today, and Tomorrow. Photogrammetric Engineering and Remote Sensing, Vol. 72, No. 10, pp. 1171-1178.

Woodcock, C.E., Allen, R., Anderson, M., Belward, A., Bindschadler, R., Cohen, W., Gao, F., Goward, S.N., Helder, D., Helmer, E., Nemani, R., Oreopoulos, L., Schott, J., Thenkabail, P.S., Vermote, E.F., Vogelmann, J., Wulder, M.A., Wynne, R. 2008. Free access to Landsat imagery. Science, Vol. 320, p. 1011.

Wulder, M.A., Seemann, D. 2001. Spatially partitioning Canada with the Landsat Worldwide Referencing System. Canadian Journal of Remote Sensing, Vol. 27, No. 3, pp. 225-231. 
Wulder, M.A., White, J.C., Cranny, M., Hall, R.J., Luther, J.E., Beaudoin, A., Goodenough, D.G., Dechka, J.A. 2008. Monitoring Canada’s Forests. Part 1: Completion of the EOSD land cover project. Canadian Journal of Remote Sensing, Vol. 34, No. 6, pp. 549-562.

Wulder, M.A., Masek, J.G., Cohen, W.B., Loveland, T.R., Woodcock, C.E. 2012. Opening the archive: How free data has enabled the science and monitoring promise of Landsat. Remote Sensing of Environment, Vol. 122, pp. 2-10. 
Table 1. Specifications for Landsat sensors operating from 1972-2012.

\begin{tabular}{|c|c|c|c|c|c|c|}
\hline Sensor & Satellite & Spectral bands & WRS & $\begin{array}{c}\text { Pixel size } \\
(\mathrm{m})\end{array}$ & $\begin{array}{c}\text { Revisit } \\
\text { (days) }\end{array}$ & $\begin{array}{c}\text { Scene } \\
\text { size }(\mathbf{k m})\end{array}$ \\
\hline MSS & $1,2,3$ & $\begin{array}{l}\text { Band 4: Visible (0.5 to } 0.6 \mu \mathrm{m}) \\
\text { Band 5: Visible }(0.6 \text { to } 0.7 \mu \mathrm{m}) \\
\text { Band 6: NIR (0.7 to } 0.8 \mu \mathrm{m}) \\
\text { Band 7: NIR }(0.8 \text { to } 1.1 \mu \mathrm{m})\end{array}$ & 1 & 60 & 18 & $170 \times 185$ \\
\hline MSS & 4,5 & $\begin{array}{l}\text { Band 1: Visible (0.5 to } 0.6 \mu \mathrm{m}) \\
\text { Band 2: Visible }(0.6 \text { to } 0.7 \mu \mathrm{m}) \\
\text { Band 3: NIR }(0.7 \text { to } 0.8 \mu \mathrm{m}) \\
\text { Band 4: NIR }(0.8 \text { to } 1.1 \mu \mathrm{m})\end{array}$ & 2 & 60 & 16 & 170 x185 \\
\hline TM & 4,5 & $\begin{array}{l}\text { Band 1: Visible }(0.45-0.52 \mu \mathrm{m}) \\
\text { Band 2: Visible }(0.52-0.60 \mu \mathrm{m}) \\
\text { Band 3: Visible }(0.63-0.69 \mu \mathrm{m}) \\
\text { Band 4: NIR }(0.76-0.90 \mu \mathrm{m}) \\
\text { Band 5: NIR }(1.55-1.75 \mu \mathrm{m}) \\
\text { Band 6: Thermal }(10.40-12.50 \mu \mathrm{m}) \\
\text { Band 7: MIR }(2.08-2.35 \mu \mathrm{m})\end{array}$ & 2 & $\begin{array}{c}30 \\
\text { (thermal: 120) }\end{array}$ & 16 & $170 \times 185$ \\
\hline ETM+ & 7 & $\begin{array}{l}\text { Band 1: Visible }(0.45-0.52 \mu \mathrm{m}) \\
\text { Band 2: Visible }(0.52-0.60 \mu \mathrm{m}) \\
\text { Band 3: Visible }(0.63-0.69 \mu \mathrm{m}) \\
\text { Band 4: NIR }(0.77-0.90 \mu \mathrm{m}) \\
\text { Band 5: NIR }(1.55-1.75 \mu \mathrm{m}) \\
\text { Band 6: Thermal }(10.40-12.50 \mu \mathrm{m}) \\
\text { Band 7: MIR }(2.08-2.35 \mu \mathrm{m}) \\
\text { Band 8: PAN }(0.52-0.90 \mu \mathrm{m})\end{array}$ & 2 & $\begin{array}{c}30 \\
\text { (thermal:60) } \\
\text { (pan: 15) }\end{array}$ & 16 & $170 \times 185$ \\
\hline
\end{tabular}


Table 2. Distribution of archived Landsat images of Canada by province and ecozone.

\begin{tabular}{lrrrrr}
\hline & MSS & TM & ETM+ & $\begin{array}{r}\text { ETM+ } \\
\text { SLC-OFF }\end{array}$ & TOTAL \\
\hline Province & & & & & \\
\hline Alberta & 4,187 & 18,163 & 2,971 & 5,595 & 30,916 \\
British Columbia & 9,168 & 27,745 & 5,547 & 8,861 & 51,321 \\
Saskatchewan & 6,004 & 19,093 & 3,014 & 5,599 & 33,710 \\
Manitoba & 4,653 & 20,765 & 3,233 & 5,533 & 34,184 \\
Ontario & 19,392 & 44,122 & 6,504 & 13,643 & 83,661 \\
Quebec & 16,937 & 50,245 & 8,157 & 12,184 & 87,523 \\
New Brunswick & 2,661 & 3,152 & 631 & 1,268 & 7,712 \\
Nova Scotia & 3,255 & 2,878 & 694 & 1,200 & 8,027 \\
Prince Edward Island & 515 & 524 & 126 & 249 & 1,414 \\
Newfoundland & 10,696 & 10,119 & 2,634 & 3,508 & 26,957 \\
Yukon & 8,097 & 14,469 & 3,788 & 5,810 & 32,164 \\
Northwest Territories & 6,786 & 50,432 & 9,489 & 11,495 & 78,202 \\
Nunavut & 5,676 & 85,257 & 16,552 & 22,705 & 130,190 \\
\hline Ecozone & & & & & \\
\hline Arctic Cordillera & 659 & 6,735 & 1,602 & 2,638 & 11,634 \\
Atlantic Maritime & 9,070 & 10,128 & 2,055 & 3,998 & 25,251 \\
Boreal Cordillera & 4,343 & 10,636 & 2,579 & 3,766 & 21,324 \\
Boreal Plains & 4,057 & 20,884 & 3,341 & 5,999 & 34,281 \\
Boreal Shield East & 18,703 & 30,440 & 5,513 & 9,289 & 63,945 \\
Boreal Shield West & 8,240 & 27,659 & 4,167 & 8,119 & 48,185 \\
Hudson Plains & 1,723 & 12,181 & 1,774 & 3,217 & 18,895 \\
Mixedwood Plains & 7,901 & 9,885 & 1,488 & 3,474 & 22,748 \\
Montane Cordillera & 4,191 & 14,374 & 2,386 & 4,456 & 25,407 \\
Northern Arctic & 6,323 & 73,281 & 14,621 & 19,086 & 113,311 \\
Pacific Maritime & 4,596 & 9,810 & 2,489 & 3,648 & 20,543 \\
Semiarid Prairies & 5,106 & 9,867 & 1,637 & 3,326 & 19,936 \\
Southern Arctic & 4,778 & 42,620 & 7,404 & 9,301 & 64,103 \\
Subhumid Prairies & 3,036 & 7,588 & 1,239 & 2,470 & 14,333 \\
Taiga Cordillera & 3,622 & 6,985 & 1,768 & 2,722 & 15,097 \\
Taiga Plains & 2,275 & 17,398 & 3,240 & 4,249 & 27,162 \\
Taiga Shield East & 7,867 & 18,824 & 3,269 & 4,129 & 34,089 \\
Taiga Shield West & 1,537 & 17,669 & 2,768 & 3,763 & 25,737 \\
\hline & & & & &
\end{tabular}




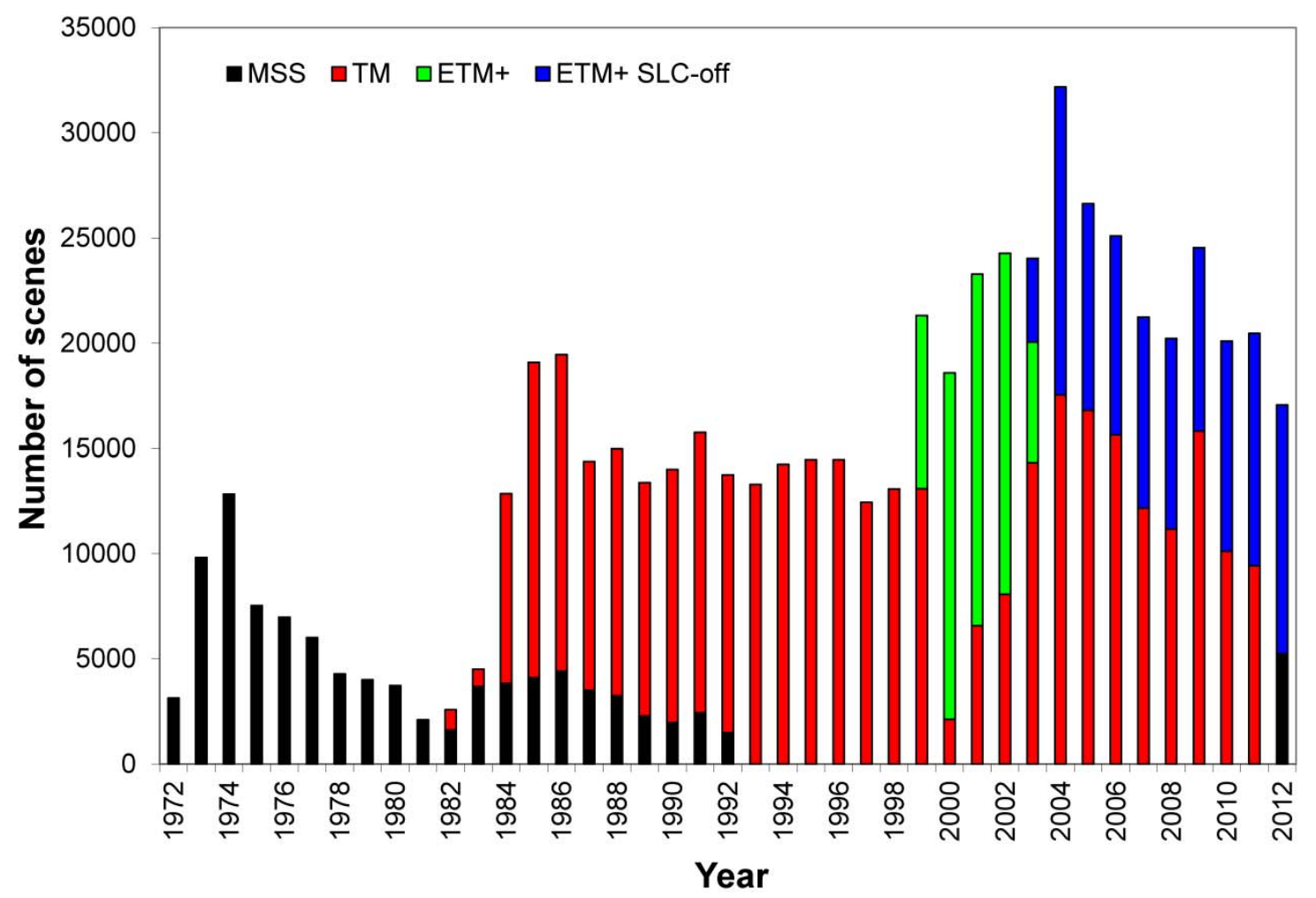

Figure 1. Total number of archived Landsat images acquired for Canada, by year and sensor. 

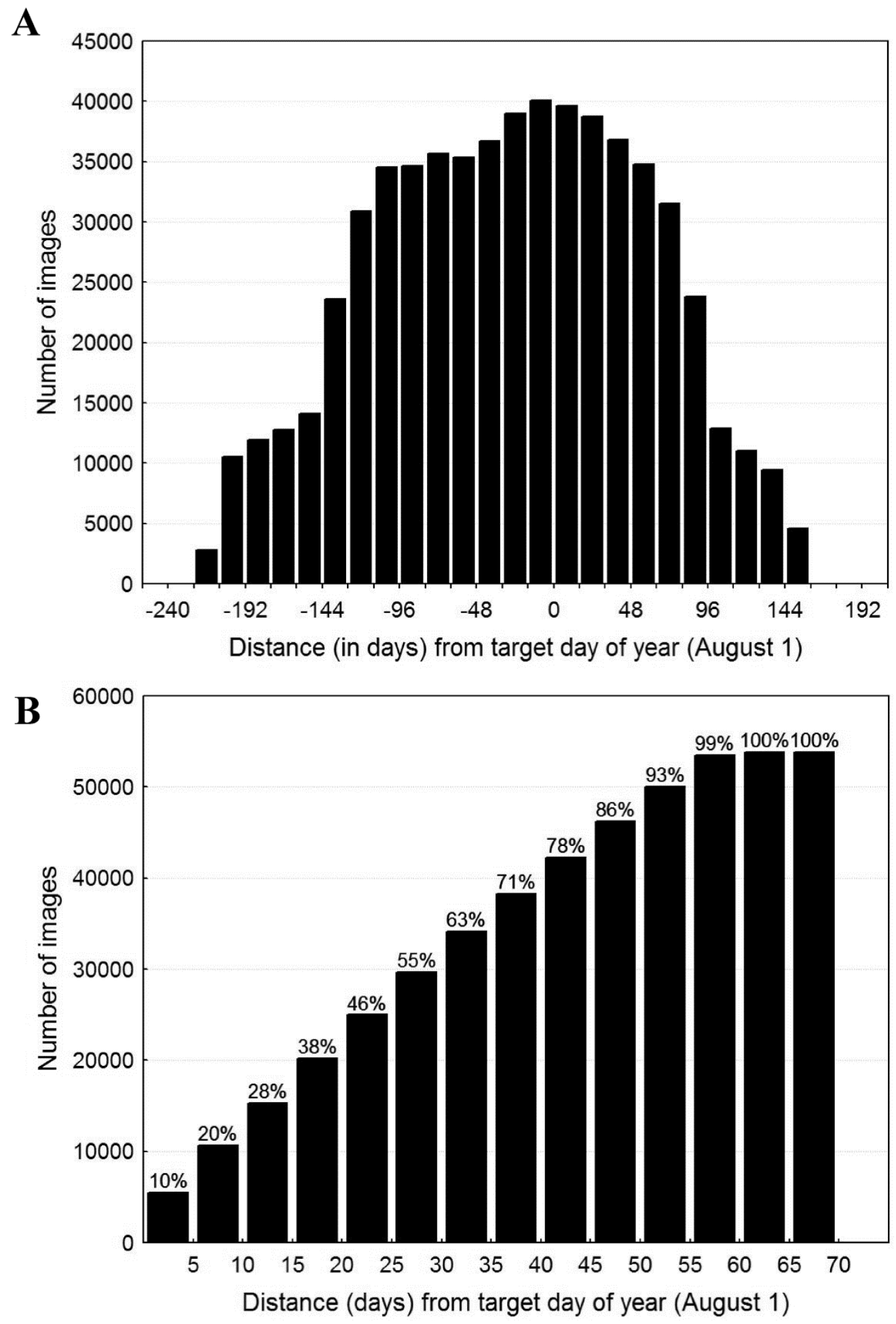

Figure 2. (A) Distance (in days) from a target day of year of August 1, and (B) cumulative distribution of archived Landsat images (all sensors) relative to August 1. 

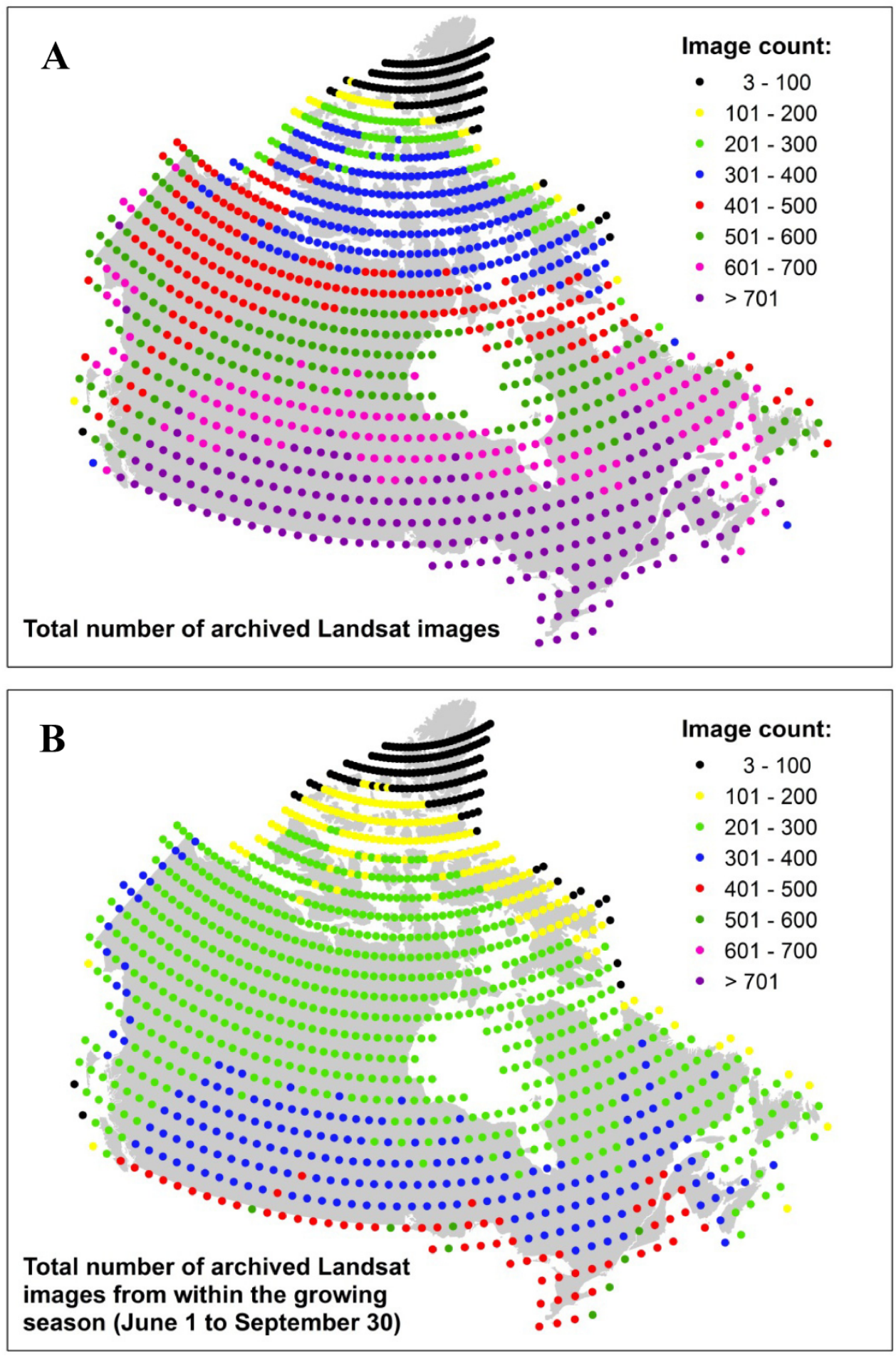

Figure 3. (A) Total number of Landsat images (all sensors) in the archive, by WRS-2 path row and (B) total number of Landsat images (all sensors) from within the growing season (June 1 to September 30). 


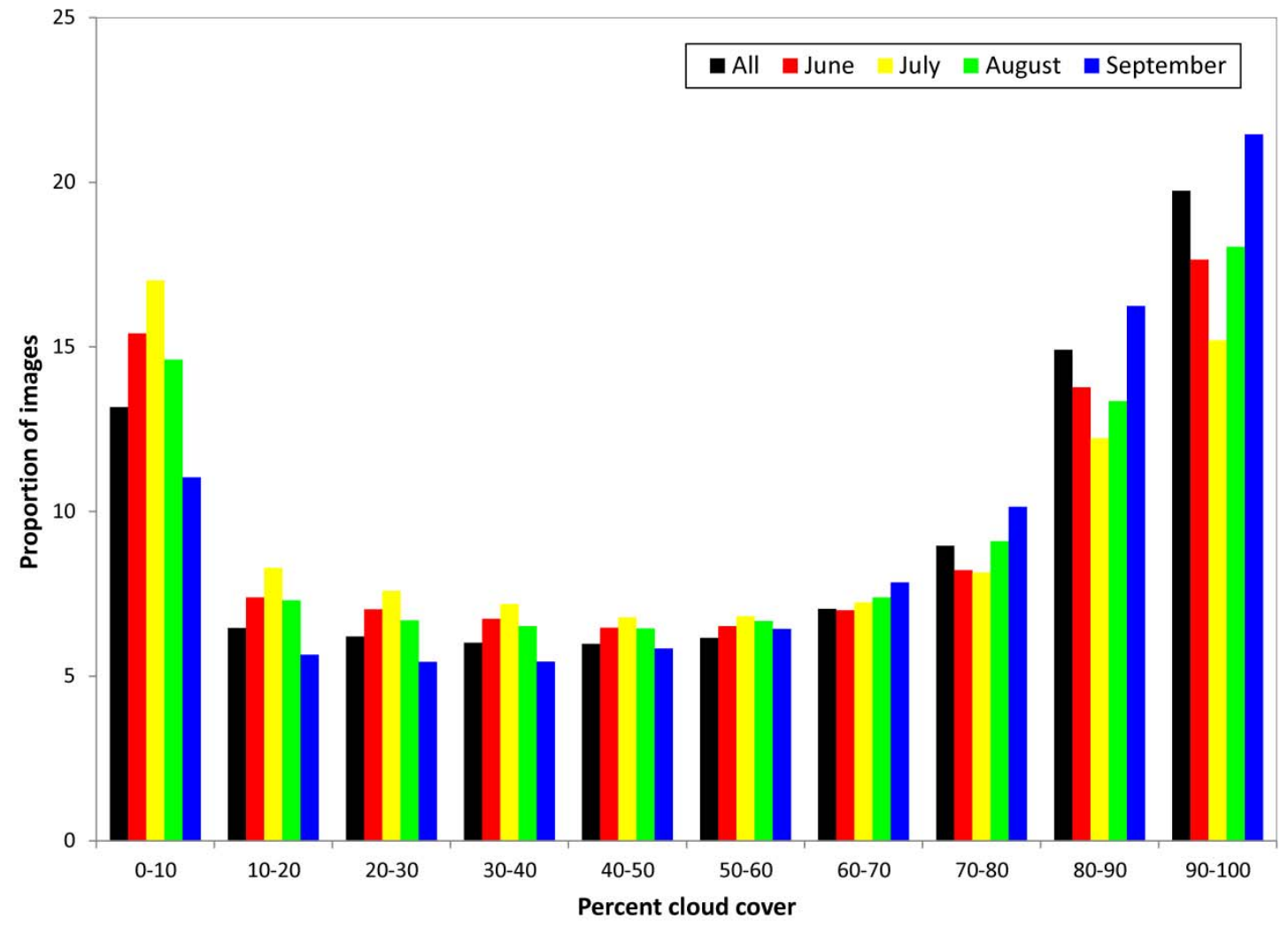

Figure 4. Distribution of archived Landsat images (all sensors) by their overall reported proportion cloud cover. 

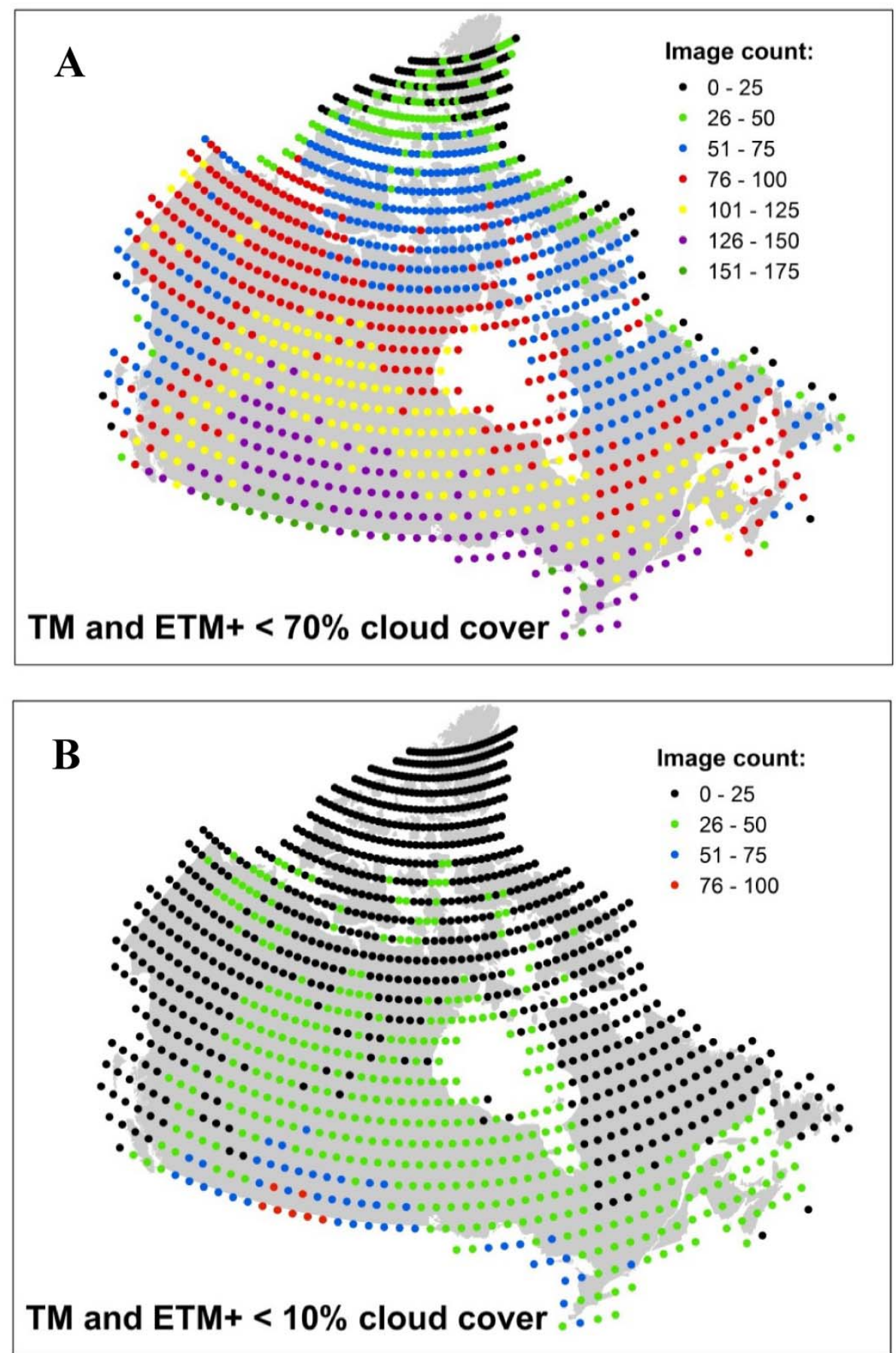

Total number of images in Landsat archive of Canada From within growing season (June 1 to September 30)

Figure 5. Spatial distribution of archived Landsat images (TM and ETM+ only) according to different cloud cover requirements. 

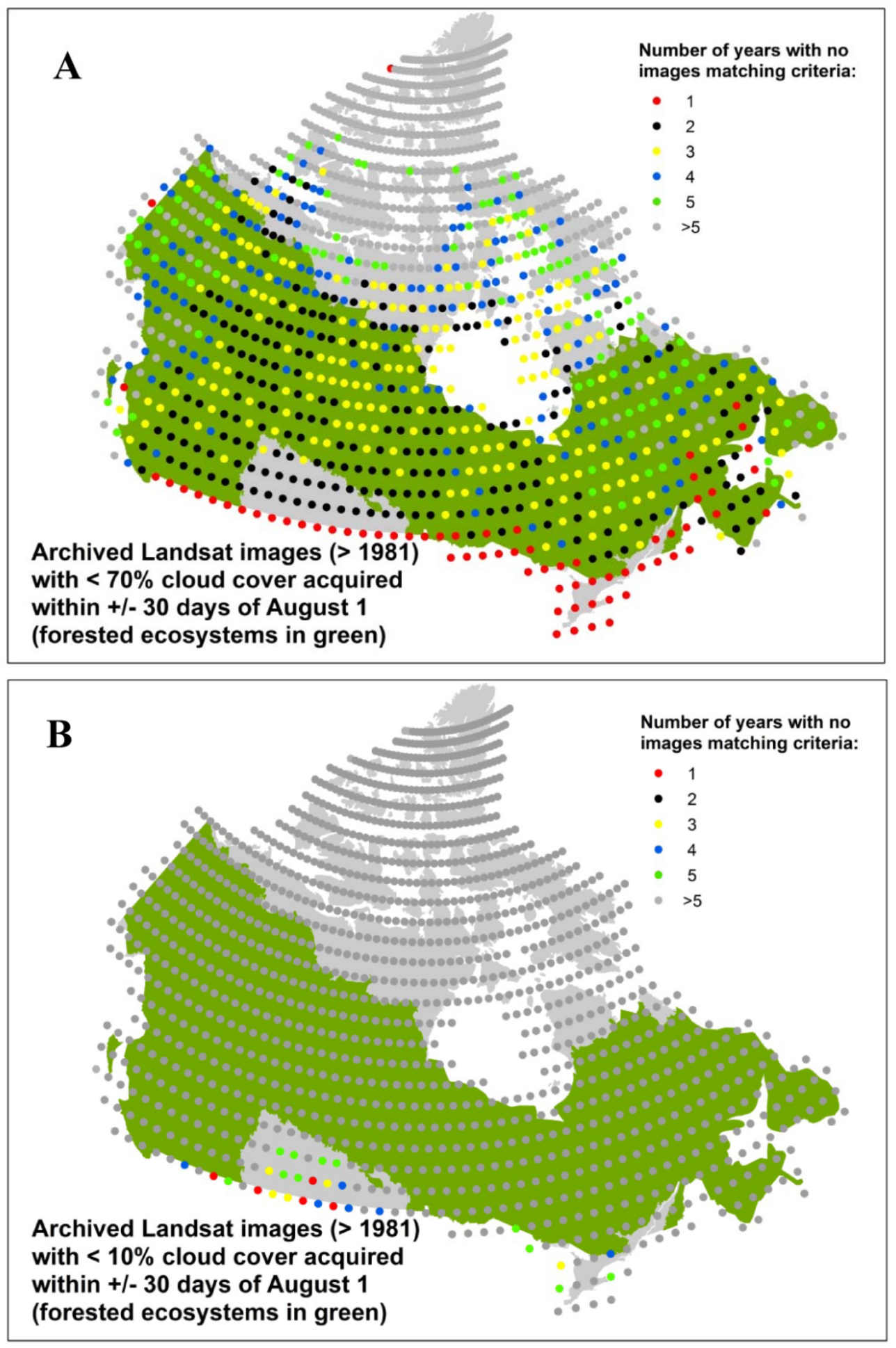

Figure 6. For each path/row location, the number of years with no images matching the specified criteria for two different scenarios used to query the Landsat archive. For a pixel-based image compositing approach, images (TM and ETM+ only) with $<70 \%$ cloud cover acquired after 1981 and within \pm 30 days of a target date (August 1 ) are considered (A). For an ecosystem monitoring scenario, images (TM and ETM+ only) with $<10 \%$ cloud cover acquired after 1981 and within \pm 30 days of a target date (August 1) (B). Forested ecosystems are shown in green. 


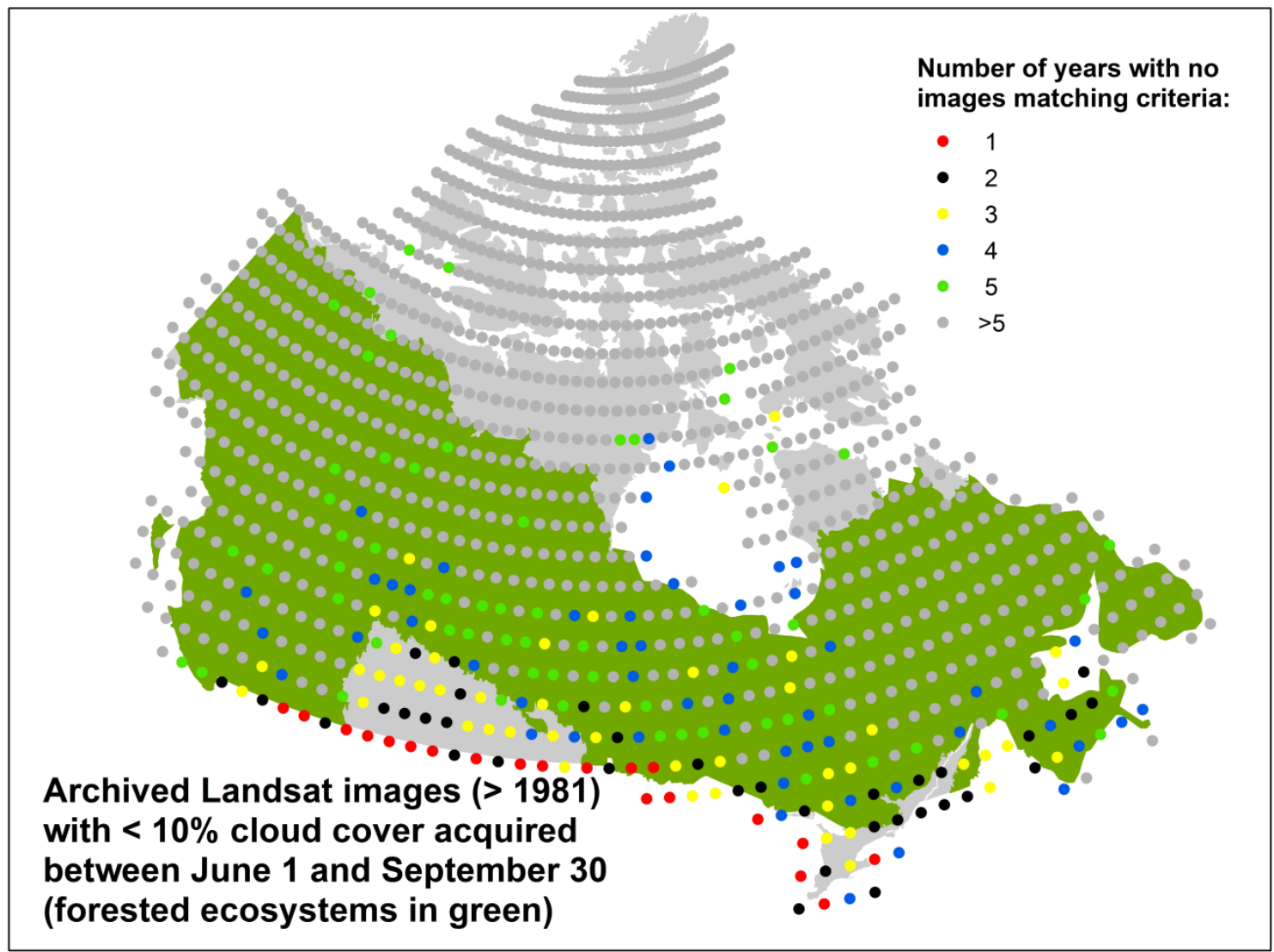

Figure 7. For each path/row location, the number of years with no images matching the specified criteria if the temporal constraint for an ecosystem monitoring scenario (see Figure 6B) is expanded from August $1 \pm 30$ days to the growing season (June 1 to September 30). 


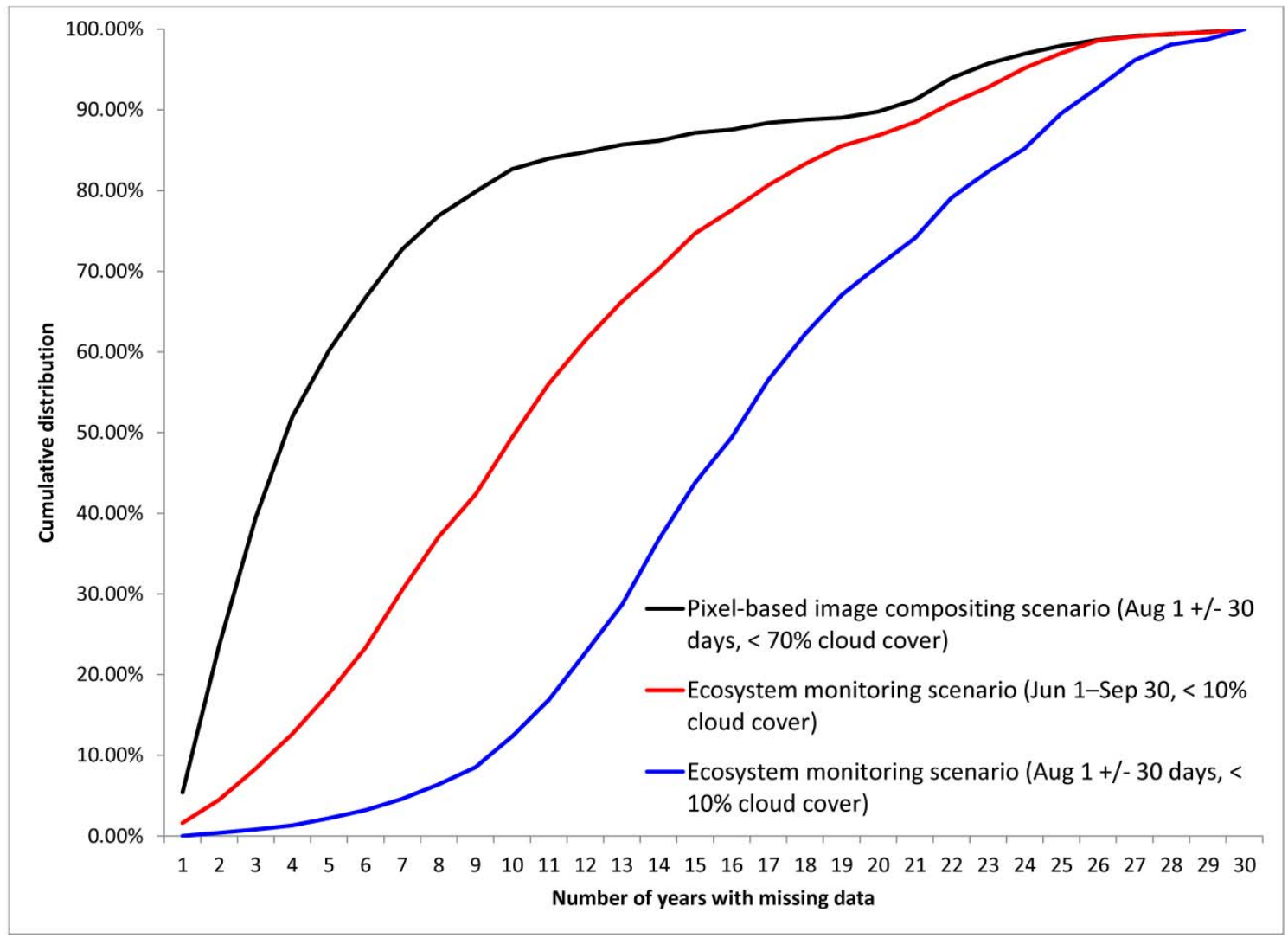

Figure 8. Cumulative frequency distribution of WRS-2 path/row locations for number of years with no images matching the specified criteria for the ecosystem monitoring or pixel-based image compositing scenarios considered. 